http://jmscr.igmpublication.org/home/

ISSN (e)-2347-176x ISSN (p) 2455-0450

crossref DOI: https://dx.doi.org/10.18535/jmscr/v9i6.40

Journal Of Medical Science And Clinical Research

\title{
Rhizomelic Chondrodysplasia Punctata- A Case Report
}

\author{
Authors \\ Dr Sunil Kumar Agarwalla ${ }^{1}$, Dr Priyadarshani Paik ${ }^{2}$ \\ ${ }^{1}$ Associate Professor, ${ }^{2}$ Junior resident \\ Dept of Paediatrics, MKCG Medical College, Berhampur, Odisha
}

\begin{abstract}
Peroxisomal diseases are a group of monogenic disorders that include defects in peroxisome biogenesis or enzyme deficiencies ${ }^{[1]}$. Rhizomelic chondrodysplasia punctata (RCDP) belongs to peroxisome biogenesis disorder caused by autosomal recessive mutation on PEX7 gene, encoding PTS 2 receptor ${ }^{[2]}$. It is characterized by rhizomelia, ichthyosis, seizure, repeated infection, congenital cataract \& joint contractures $^{[1]}$. Radiological features include epiphyseal stippling, coronal clefts in vertebral bodies. Here we are reporting a case of $R C D P$ in an infant because of its rarity.

Keywords: Peroxisome, Rhizomelia, Autosomal recessive, cataract, contracture.
\end{abstract}

\section{Introduction}

Rhizomelic chondrodysplasia punctata (RCDP) is a rare autosomal recessive disorder characterized by proximal shortening of arms \& legs, congenital cataract, contractures, ichthyosis, seizure \& repeated infections. Radiological features of RCDP are punctate epiphyseal calcification, metaphyseal abnormalities \& coronal clefts ${ }^{[3]}$. RCDP carries poor prognosis with approximately $60 \%$ \& 39\% cases surviving the first \& second year respectively ${ }^{[4]}$. We report a case of RCDP which was diagnosed based on clinical \& radiological features.

\section{Case Report}

A 50 day male young infant presented to OPD for evaluation of short limbs \& acute respiratory tract infection. He was $2^{\text {nd }}$ order child born term, birth weight of $2.9 \mathrm{~kg}, \quad$ LSCS with $3^{\text {rd }}$ degree consanguineous marriage. $1^{\text {st }}$ child of parents had similar history which died at 1 year of life. There was no history of any maternal disease or drug exposure. The physical examination showed weight $3.05 \mathrm{~kg}(<-3 \mathrm{SD})$, length $53 \mathrm{~cm}$ (-3SD to 2SD), head circumference $36 \mathrm{~cm}$ (-2SD to $-1 \mathrm{SD})$. His upper to lower segment ratio was 1.6:1 which is normal. He had proximal shortening of both upper \& lower limbs. He had frontal bossing with flat facial features with anteverted nares. Ophthalmological examination revealed both eye cataract. The pinna was normal shaped \& positioned. There was rough skin with hyperpigmentation. His abdomen was soft with no organomegaly.

A Skeletal survey demonstrated rhizomelic micromelia in bilateral lower limbs. There was stippled calcification noted in region of proximal $\&$ distal epiphysis of bilateral humeri \& femuri. Vertebrae are normal in height and anterior coronal cleft. 2D-ECHO was done on day 2 of life showing small secondary ASD (3.2mm) with good left ventricular \& right ventricular function. 
Extended new-born screening for IEM was done which showed no abnormality. Other biochemical $\&$ thyroid profile was normal.

A

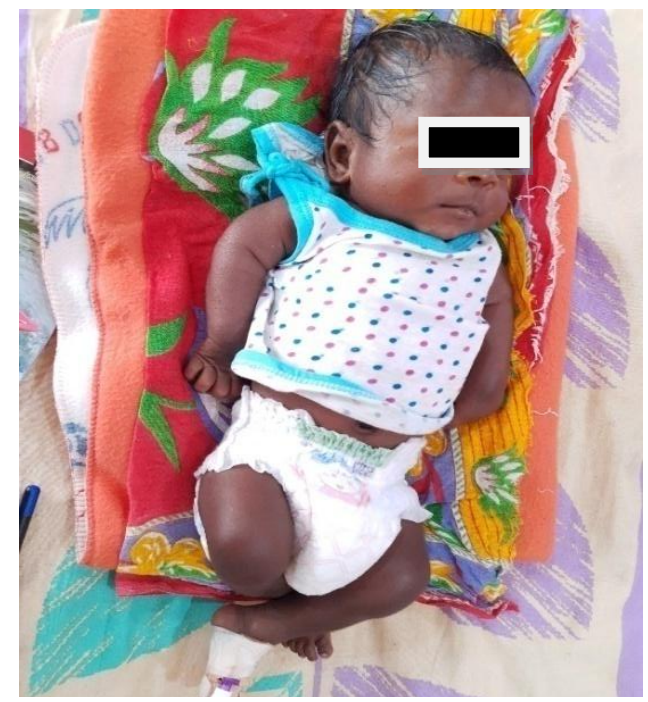

B

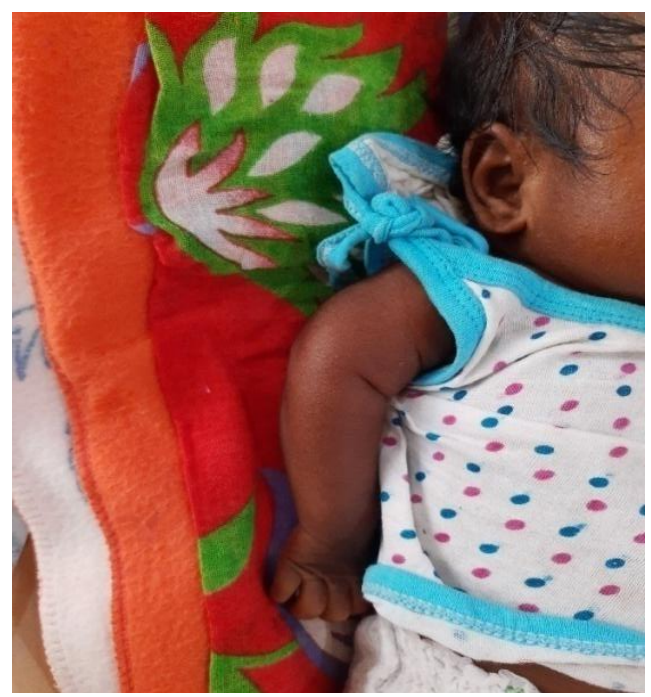

Fig A \& B showing shortened proximal limbs.

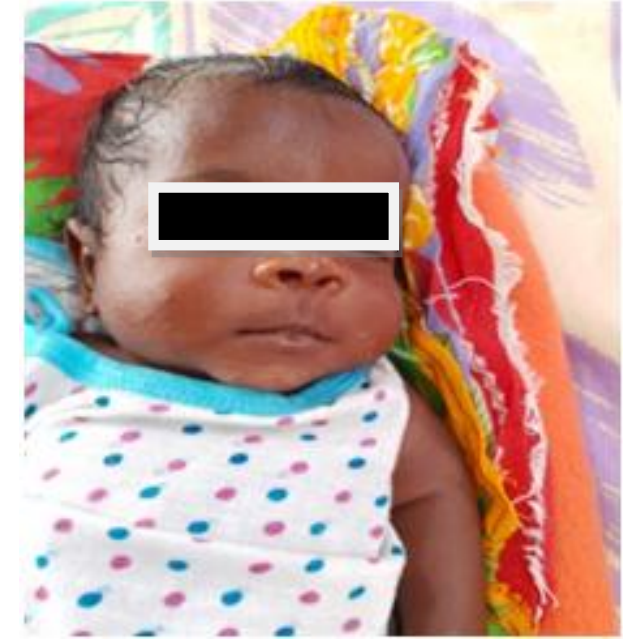

Fig 1

Fig 1 showing anteverted nares

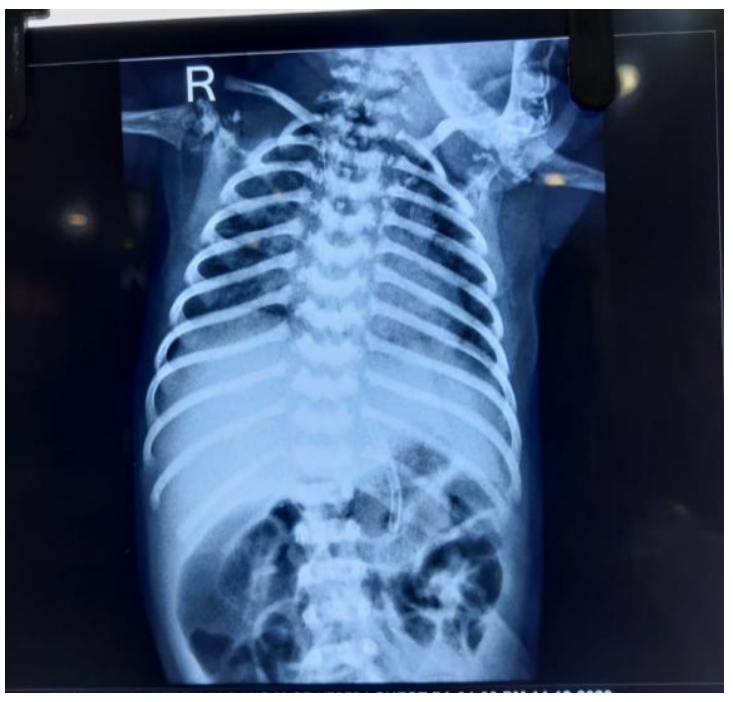

Fig 2

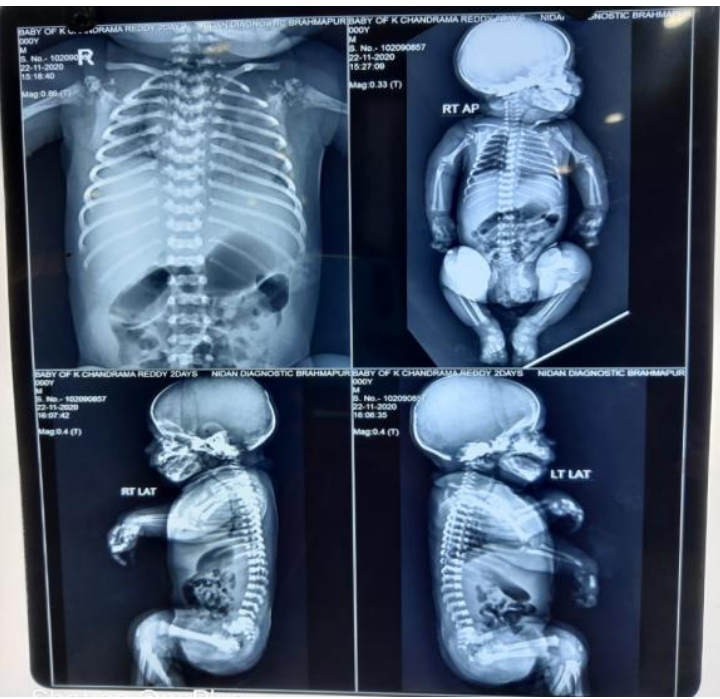

Fig 3

Fig 2 \& 3 showing rhizomelic micromelia, stippled calcification, and coronal Clefts in vertebral bodies

\section{Discussion}

Rhizomelic chondrodysplasia punctata (RCDP) is a peroxisomal disorder characterized by rhizomelic proximal shortening of humerus and femur, ichthyosis, cataract, restricted joint mobility, flat facial appearance. Patient may develop seizure \& psychomotor delay ${ }^{[5]}$. Radiological features of RCDP include epiphyseal stippling, metaphyseal abnormalities \& cleft in vertebral bodies. Most of these classical findings are present in our case. Most affected children develop repeated respiratory infection \& die within 2 years of life ${ }^{[6]}$. 
The diagnosis of RCDP is based on clinical findings and radiological abnormalities. Biochemical assays which are confirmatory for diagnosis include plasma phytanic acid levels, red cell plasmalogen deficiency, deficiency of dihydroxyacetone phosphate acyltransferase \& normal concentration of very long chain fatty $\operatorname{acids}^{[7]}$. Gene sequencing can be performed to detect PEX7 gene mutation.

Management of these babies is mainly supportive $\&$ limited by multiple anomalies \& poor outcome. Cataract extraction may give vision in some cases. Physiotherapy is recommended to improve contractures \& orthopaedic procedure may improve functions in some extent. Monitoring of growth, development, vision, hearing, contractures $\&$ orthopaedic complications are required in these children to follow-up.

Genetic sequencing \& molecular diagnosis was not possible in our set-up. Therefore such rhizomelic baby with $1^{\text {st }}$ sibling death due to similar illness \& both eye cataract points towards an entity of RCDP. After counselling parents didn't agree for further course of investigation. The rarity of this case hinted us to go for reporting depicting the importance of clinical examination is paramount importance even in 21 st century.

\section{References}

1. Weller S, Gould S. J, Valle D. (2003). "Peroxisome Biogenesis Disorders" Annual Review of Genomics and Human Genetics. 4:165-211. doi:

10.1146/annurev.genom.4.070802.110424. PMID14527301. [PubMed] [Google Scholar]

2. Moser A, Moser H, Kreiter N, Raymond G. Life expectancy in rhizomelic chondrodysplasia punctata. Am J Hum Genet 1996; 59: 99.
3. Braverman NE, Moser AB, Steinberg SJ. Rhizomelic Chondrodysplasia Punctata Type 1. In: Pagon RA, Bird TD, Dolan CR, Stephens K, editors. Gene Reviews [Internet]. University of Washington, Seattle; 2001 Nov 16. Accessed on 8 April, 2013.

4. Available from: http://www.ncbi.nlm.nih.gov/books/ NBK1270/

5. Irving M. D, Chitty L. S, Mansour S, Hall C. M. "Chondrodysplasia punctata: a clinical diagnostic and radiological review," Clinical Dysmorphology. 2008; 17(4):229-241. View at Publisher-View at Google Scholar-View at Scopus. [PubMed] [Google Scholar]

6. White A. L, Modaff P, Holland-Morris F, Pauli R. M. "Natural history of rhizomelic chondrodysplasia punctata," American Journal of Medical Genetics. 2003; 118(4):332-342. View at Scopus. [PubMed] [Google Scholar]

7. Morrison S. C. "Punctate epiphyses associated with Turner syndrome," Pediatric Radiology. 1999;29(6):478480. View at Publisher - View at Google Scholar - View at Scopus. [PubMed] [Google Scholar] 